\title{
Model for the assessment greenhouse gas emissions from road transport
}

\author{
Yu.V. Trofimenko ${ }^{1}$, V.I. Komkov ${ }^{2}$, V.V. Donchenko ${ }^{3}$, T.D. Potapchenko ${ }^{4}$ \\ ${ }^{1}$ Moscow Automobile and Road Construction State Technical University (MADI) \\ Leningradsky avenue, 64, Moscow, Russia \\ ${ }^{2}$ Moscow Automobile and Road Construction State Technical University (MADI) \\ Leningradsky avenue, 64, Moscow, Russia \\ ${ }^{3}$ Joint-stock Company «Scientific and Research Institute of Motor Transport», Moscow, Russia \\ ${ }^{4}$ Moscow Automobile and Road Construction State Technical University (MADI) \\ Leningradsky avenue, 64, Moscow, Russia
}

Received Dec 8, 2018

\section{Keyword:}

Road transport

Mobile and stationary

facilities

Greenhouse gas emissions

Emission forecast

\begin{abstract}
A three-level model for estimating greenhouse gas (GHG) emissions by mobile and stationary road transport facilities of a state or region, proposed in this article, takes account into GHG emissions from a vehicle fleet (mobile objects) and road transport infrastructure (network of car services, road network of various categories).

Additionally, it has been developed the intellectual system which evaluates the reliability of the array of initial data, by increasing the range and adjusting (if necessary) the values of individual indicators, as the result we achieving the convergence of the calculating GHG emissions from motor vehicles according to the models of all three levels of assessment. This ensures verification of the obtained gross GHG emissions.

Evaluation of greenhouse gas emissions using three-level model was carried out for St. Petersburg and the Leningrad Region (Russian Federation), they shown the possibility of reducing by 2030 by $3.2 \ldots$ $12.4 \%$ of gross GHG emissions by motor transport of the Russian Federation in comparison with 2015. For St. Petersburg and the Leningrad Region, both the reduction of gross GHG emissions by road transport (12.7\% innovative scenario) and their growth (4.8\% inertial scenario) are expected during the forecast period. At the same time, both for the St. Petersburg and the Leningrad Region and for the state as a whole, a significant reduction in gross GHG emissions by road transport is expected in the period after 2025 due to the intensive replacement of cars on oil fuel by electric vehicles and hybrids, changes in the transport behavior of the population, the development of public passenger transport and cycling, the introduction of autonomous vehicles, etc.
\end{abstract}

\section{Corresponding Author:}

Yu.V. Trofimenko,

Moscow Automobile and Road Construction State Technical University (MADI)

Leningradsky avenue, 64, Moscow, Russia, 125319.

Email: ywtrofimenko@mail.ru 


\section{Introduction}

Ensuring the transition of transport sector to a low-carbon model of development should be the key vector of modern transport policy, which is impossible without the creation of an effective system of accounting, monitoring and forecasting of gross greenhouse gas $(\mathrm{GHG})$ emissions by individual types of transport and primarily by road transport, which, for example, in the Russian Federation accounts for $2 / 3$ of gross GHG emissions by all types of transport [1]. Such a system for recording, monitoring and forecasting GHG emissions from a region or a state can be created using mathemat-ical modeling methods based on the implementation of the methodological principles of the United Nations International Panel on Climate Change (IPCC) [2], accounting for GHG emis-sions primarily from mobile vehicles (motor vehicles [3] or road traffic on the road network). For the estimation of initial data in such calculations can be used the models of estimation of characteristics of traffic flows, for example, given in [4] and [5].

In addition to GHG emissions by mobile road transport facilities, quite a lot of GHG is emitted by road transport infrastructure facilities (car service network, other facilities of production and technical base, as well as the road network), which should also be taken into account [1].

Considering that part of the source data cannot be determined based on the results of statistical analysis or field measurements, but only by calculation, it is important to verify the results of estimat-ing GHG emissions, which can be performed using different methods [6] and [7].

\section{Methodology for the forecasting of greenhouse gas emissions}

The quantitative assessment of the values of gross GHG emissions by mobile sources (vehicle fleet) and infrastructure facilities (network of production and technical facilities (PTF) and roads) in the developed three-level calculation model was carried out using the formulas presented in table 1 and based on the methodological approach [2] [8] [9], as well as the results of studies carried out with the participation of the authors.

Table 1 Equations used to estimate climate gases emission from transport in a region or state for different levels of detail of the baseline data, $t$ /year

\begin{tabular}{|c|c|c|}
\hline $\begin{array}{l}\text { Object of } \\
\text { estimation } \\
\text { of GNG } \\
\text { emission }\end{array}$ & Equation & Designations (comments) \\
\hline $\begin{array}{l}\text { Mobile } \\
\text { facilities } \\
\text { (vehicle } \\
\text { fleet) } \\
\text { Levels } 1,2\end{array}$ & $E_{C O 2}=\sum_{a}\left(A D_{a} \cdot E F_{a}\right) / 10^{3}$ & $\begin{array}{l}\mathrm{E} \text {-emission of } \mathrm{CO}_{2}, \mathrm{CH}_{4} \text { or } \mathrm{N}_{2} \mathrm{O}, \mathrm{t} / \mathrm{year} \text {; }- \\
\text { transport mode (road, urban electric, rail, air, } \\
\text { water); } \mathrm{ADa}-\text { volume of transport work of a } \\
\text { transport mode (passenger or freight } \\
\text { transportation), mln. } \mathrm{t} \text { km or pass.-km/year; } \mathrm{EFa}- \\
\mathrm{CO}_{2} \text { specific emission (emission coefficient) for a } \\
\text { transport mode (passenger or freight } \\
\text { transportation), } \mathrm{kg} / \mathrm{t} \mathrm{km} \text { or pass.km. }\end{array}$ \\
\hline $\begin{array}{l}\text { Mobile } \\
\text { facilities } \\
\text { (vehicle } \\
\text { fleet) } \\
\text { Level } 3\end{array}$ & $E=\frac{\left.\left(\sum_{a, b, c, d}\left(A D_{a, b, c, d} \cdot E F_{a, b, c, d}\right)+\sum_{a, b, c, d} C_{a, b, c, d}\right)\right)}{10^{6}}$ & $\begin{array}{l}\mathrm{E}-\mathrm{CO}_{2}, \mathrm{CH}_{4} \text { or } \mathrm{N}_{2} \mathrm{O} \text {, emission, t/year; a - type of } \\
\text { fuel (diesel, petrol, } \mathrm{LPG} \text {, electricity); } \mathrm{b} \text { - vehicle } \\
\text { type; c - environmental class; } \mathrm{d}-\text { conditions of } \\
\text { operation (urban or rural roads); } \mathrm{AD}_{\mathrm{a}, \mathrm{b}, \mathrm{c}, \mathrm{d}}-\text { annual } \\
\text { mileage on d type roads of b class vehicles, which } \\
\text { work on type a fuel and have c, environmental } \\
\text { class, km; } \mathrm{EF}_{\mathrm{a}, \mathrm{b}, \mathrm{c}, \mathrm{d}}-\mathrm{CO}_{2}, \mathrm{CH}_{4} \text { or } \mathrm{N}_{2} \mathrm{O} \text { specific } \\
\text { emission for b class vehicles, which use a type } \\
\text { fuel and have environmental class c on d, type of } \\
\text { roads, g/km; } \mathrm{C}_{\mathrm{a}, \mathrm{b}, \mathrm{c}, \mathrm{d}}-\text { emission during start and } \\
\text { warming-up of engines (cold start), g/year. }\end{array}$ \\
\hline $\begin{array}{l}\text { Road } \\
\text { transport } \\
\text { (stationary }\end{array}$ & $E_{\mathrm{CO}_{2}}=\left[\sum_{k=1}^{h}\left(Y_{k} \cdot Z_{k} \cdot N_{k} \cdot L_{k}\right)\right] / 10^{6}$ & $\begin{array}{l}E_{\mathrm{CO} 2}-\mathrm{CO}_{2} \text { gross emission, t/year; } h-\text { number of } \\
\text { vehicles types; } Y_{k}-\text { specific energy resources } \\
\text { consumption at motor transport enterprisers for } k\end{array}$ \\
\hline
\end{tabular}




\begin{tabular}{|c|c|c|}
\hline $\begin{array}{l}\text { facilities), } \\
\text { (level 2) }\end{array}$ & & $\begin{array}{l}\text { type vehicles warming-up, manoeuvring, } \\
\text { servicing and repairs }, \mathrm{kWt} h / \mathrm{km} \text { of running }\left(\mathrm{M}_{1} \text {, }\right. \\
\left.\mathrm{N}_{1}-0,1737 ; \mathrm{M}_{2}, \mathrm{~N}_{2}-0,1483 ; \mathrm{M}_{3}, \mathrm{~N}_{3}-0,1102\right) ; \\
N_{k}-\text { total number of } k \text { type vehicles; } L_{k}-\text { total } \\
\text { mileage of } k \text { type vehicles, km/year; } Z_{k}-\text { specific } \\
\text { values of GNG emission factor per unit electricity } \\
\text { consumed at motor transport stationary object } \\
\text { (enterpriser), g/kWt h }\left(\mathrm{CO}_{2}-435 ; \mathrm{CH}_{4}-0,00723 ;\right. \\
\left.\mathrm{N}_{2} \mathrm{O}-0,0033\right) \text {. }\end{array}$ \\
\hline $\begin{array}{l}\text { Stationary } \\
\text { facilities } \\
\text { (road } \\
\text { network) } \\
\text { Level } 1\end{array}$ & $E_{i}=\sum_{a} \sum_{k}\left(F C_{a k} \cdot E F_{a T C E} \cdot E F_{a N C V} \cdot E F_{i, a}\right)$ & $\begin{array}{l}E_{l} \text {-emission of climate gase } i, \mathrm{t} / \mathrm{year} ; F C_{a k}-\text { total } \\
\text { mass of } a \text { energy resource consumed on roads of } \\
\text { technical category } k, \mathrm{t} / \mathrm{year} ; E F_{a T C E}-\text { converting } \\
\text { coefficient to tons of equivalent fuel by type of } \\
\text { energy resource } a \text {, t.e.f./t; } E F_{a N C V}-\text { coefficient for } \\
\text { converting in energy units by type of energy } \\
\text { resource } a \text {, TJ/t.e.f.; } E F_{i, a}-\text { coefficient of climate } \\
\text { gas emission by type of energy resource } a, \mathrm{t} / \mathrm{TJ} \text {. }\end{array}$ \\
\hline $\begin{array}{l}\text { Stationary } \\
\text { facilities } \\
\text { (road } \\
\text { network) } \\
\text { Level } 2\end{array}$ & $E_{\mathrm{CO}_{2}}=\sum_{y} \sum_{k}\left(E F_{y C O_{2}} \cdot L_{k}\right)$ & $\begin{array}{l}E_{\mathrm{CO} 2}-\mathrm{CO}_{2} \text { emission, t/year; } \mathrm{EF}_{y \mathrm{CO} 2}-\mathrm{CO}_{2} \\
\text { specific emission on roads of } k \text { technical category } \\
\text { at different stages of road`s life cycle, t/km of } \\
\text { length; } L_{k}-\text { length of road of } k \text { technical category, } \\
\mathrm{km} \text {. }\end{array}$ \\
\hline
\end{tabular}

The calculation of GHG emissions is carried out in parallel by the formulas with different level of detail of the input data and various assumptions (Levels 1-3). At Level 1, it is used a minimum set of input data and the calculation of gross GHG emissions is performed at a known mass of the burned fuel without separation into vehicle types. It also uses data on the mass of fuel consumed and GHG emission factors for motor fuels. At Level 2, GHG emissions are calculated for a known mass of burned fuel divided by environmental class (age) of different vehicle types, and GHG emission factors normalized per unit mass of burned fuel are used. At Level 3, GHG emissions are calculated with taking into account annual mileage divided into environmental classes of the vehicle. It requires detailed data on the operating conditions of the vehicle, their age, environmental class, climatic factors that affect the GHG emission factors of individual subcategories of the vehicle and are determined by the results of mathematical modeling.

The estimation of GHG emissions by stationary facilities of motor transport infrastructure-a network of car services (motor transport enterprises) is proposed to be carried out by the method of Level 2 using the experimentally established specific energy costs in the combustion of fuel and other types of energy consumed in car services for maintenance and repair of vehicles per unit of mileage of different types of vehicles and specific GHG emissions per unit of energy consumed.

It is proposed to estimate GHG emissions from the road network in their life cycle using the Level 1 method by the mass of energy consumed in the year under review, without taking into account the length of roads. The Level 2 method is similar to the Level 1 method, but here it is proposed to use the initial data on the length of roads of different categories, built, repaired, in operation during the year and specific energy costs (per unit length of road) in the construction (reconstruction) period, maintenance, repair (overhaul) of roads, as well as specific $\mathrm{CO}_{2}$ emissions during the life cycle of roads (table 2).

Table 2 Specific $\mathrm{CO}_{2}$ emissions on roads of different categories (Russian Federation, 2015), $\mathrm{tCO}_{2} / \mathrm{km}$ length (MADI data, FAU «ROSDORNII» data)

\begin{tabular}{|llccccc|}
\hline \multirow{2}{*}{$\begin{array}{l}\text { Type } \\
\text { road }\end{array}$} & of the Stage of the life cycle & \multicolumn{5}{c|}{ Technical category of the road } \\
\cline { 3 - 7 } & & I & II & III & IV & V \\
\hline Federal roads & maintenance & 43.73 & 25.00 & 16.22 & 14.09 & 11.65 \\
\cline { 2 - 7 } & repair & 533.28 & 271.70 & 195.84 & 190.16 & 52.05 \\
\cline { 2 - 7 } & major repair & 1556.92 & 713.82 & 544.34 & 526.10 & 175.33 \\
\cline { 2 - 7 } & construction & 2958.14 & 1356.26 & 1034.25 & 999.6 & 333.13 \\
\hline
\end{tabular}


PEN Vol. 7, No. 1, June 2019, pp.465- 473

\begin{tabular}{|llccccc|}
\hline $\begin{array}{l}\text { Regional and } \\
\text { inter-municipal }\end{array}$ & maintenance & 10.93 & 6.25 & 4.06 & 3.52 & 2.91 \\
\cline { 2 - 7 } & repair & 133.32 & 67.93 & 48.96 & 47.54 & 13.01 \\
\cline { 2 - 7 } & major repair & 389.23 & 178.46 & 136.09 & 131.53 & 43.83 \\
\cline { 2 - 7 } & construction & 739.54 & 339.07 & 258.56 & 249.9 & 83.28 \\
\hline $\begin{array}{l}\text { Local (hard or } \\
\text { transitional } \\
\text { coating) }\end{array}$ & maintenance & 2.19 & 1.25 & 0.81 & 0.71 & 0.58 \\
\cline { 2 - 7 } & repair & 26.66 & 13.59 & 9.79 & 9.51 & 2.60 \\
\cline { 2 - 7 } & major repair & 77.85 & 35.69 & 27.22 & 26.31 & 8.77 \\
\hline
\end{tabular}

The Level 2 model does not take into account GHG emissions from unpaved roads, road infrastructure (asphalt plants, etc.).

It should be noted that the implemented three-level model of GHG emissions assessment requires verification of the results, due to the fact that the calculation is made according to the formulas (table 1) with different levels of detail of the initial data, which can be determined in different ways with different levels of reliability. As a result, the simultaneous use of calculation methods with different degrees of data detail, at some point, for the same object can be a large discrepancy between the values of gross GHG emissions.

The verification of the obtained results of calculation of GHG emissions by road transport with using model of different levels, can be carry out using the method of machine learning (Frank Eibe, Mark A. Hall. 2011). The method of machine learning is based on the algorithm of intellectual analysis of initial data and obtaining adequate results of calculations, the scheme of which is shown in Fig. 1

Formation (preparation and input) of the database of initial data-preliminary processing of values of the separate indicators received from official statistics, by results of supervision, calculations on the known models

\section{Feature selection}

For example, for models of Levels 1 and 2, the calculation of GHG emissions by the vehicle fleet is based on data on the consumption of motor fuel vehicles

Clustering based on common features - calculation levels $(1,2,3)$, types of objects (mobile vehicle parks, stationary - auto service network, road network, street-road network)

Building a decision tree-variant calculation of GHG emissions depending on the set (nomenclature) of input data for different levels of models and objects

Search for associative rules - identifying links between variables in the source database and the results of variant calculations of GHG emissions. For example, detailed data on the annual mileage of different groups of vehicles can lead to an increase in GHG emissions; also an increase in fuel consumption leads to an increase in GHG emissions. At this stage, the program establishes connections and patterns, i.e. learns to detect a mismatch error.

\section{Regression analysis}

For example, in the Level 2 methodology, GHG emission factors depend on the amount of carbon in motor fuel, which is determined by regional fuel suppliers, which makes it possible to assign the amount of carbon to independent variables. At the same time, the value of emission factors depends on the information provided by the suppliers. Regression analysis allows to establish reliable values of the coefficient.

Finding the optimal solution - is an iterative process of achieving the level of convergence of GHG emissions assessment results by regional or state automobile transport using models of different levels (difference of values not exceeding 5\%) with varying set of input data with validation of their values. Visualization of results.

Figure 1. The diagram of the algorithm for mining the initial data and obtaining adequate results of calculations 
The proposed algorithm of machine learning is based on the establishment of links on the characteristic description (clustering, i.e. learning without a teacher). The task is to cluster, i.e. to find an atypical object (value) in the training sample of numbers. It should be noted that widely used methods of machine learning ("Random Forest" and "Delta rule") are not suitable for the task of verification, due to the fact that they are based on the use of a large number of decision trees. This increases the probability of an error in the classification of objects, and therefore the gradient descent method (the method of finding the local extreme (minimum or maximum) presented below was used.

So, let $\left(x_{1}, y_{1}\right),\left(x_{2}, y_{2}\right) \ldots .\left(x_{n}, y_{n}\right)$ is the training sample (in the case of using the model of Level 1 estimation of GHG emissions is the mass of fuel consumption), $\mathrm{Y}=1,2 \ldots \mathrm{c}-$ many classes (type of fuels).

To identify errors in the classification, the value of «indent» used:

$$
M\left(x_{i}, y_{i}\right)=g_{y i}\left(x_{i}\right)-\max _{y \in Y} /\left\{y_{i}\right\} g_{y}\left(x_{i}\right)
$$

If the indent is negative, it means that object $x_{i}$ was incorrectly classified, i.e. the indentation value shows how confident the classifier is that object $x_{i}$ can be assigned to the true class $y_{i}$.

In this case, objects that are strongly out of the established pattern determined by the learning algorithm are determined by the formula:

$$
\left[x_{i} ; M\left(x_{i}, y_{i}\right)\right]<-\mu
$$

where $\mu$ - is the total number of sampling.

Accordingly, in the learning process for each $\left(x_{i}, y_{i}\right)$ value in the training sample $\mathrm{T}$ is necessary to calculate $M\left(x_{i} y_{i}\right)$ by the formula:

$$
T=\left[\left(x_{i}, y_{i}\right) ; M\left(x_{i}, y_{i}\right) \geq-\mu\right]
$$

It can be concluded that the verification of the results of the GHG emission estimation model is to develop an algorithm that depends on the parameters and allows to determine the value of the class label $(Y)$ for the new object $(x)$.

At the same time, in order to improve the efficiency of verification of the results, at a separate stage, the problem of optimization of traffic flows is considered, the solution of which allows for additional verification through comparison of data on flows and the fuel consumption, using the function of the form:

$$
\begin{aligned}
& F(x, u) \rightarrow \text { extreumum, } \\
& G(x, u)=0, \\
& u \in U,
\end{aligned}
$$

where $x$ is the state of the system, $G$ is the link between the state and control variables; $U$ is the set of control parameters; $F$ is the objective function.

The set $U$ is the set of traffic flow controls on the road or road network. In a generalized sense, these are all the parameters on which the behavior of traffic flows depends and which are amenable to changes at one or another speed [10].

Using the above algorithm, the developed intelligent system evaluates the reliability of the array of input data and by increasing the range and adjusting (if necessary) the values of individual indicators in the formulas given in table 1, we achieve the convergence of the results of calculations of GHG emissions by road transport using models of Levels 1,2,3. This ensures the verification of the obtained values of gross GHG emissions by investigated type of transport.

The developed model makes it possible to estimate gross GHG emissions by road transport of a region or a state both in retrospect and in the future. For predictive estimates in the developed model is added block scenario prediction values of the source data in the Models of levels 1-3 for a given period in the implementation of different activities.

\section{Scenarios forecasting the initial data of the estimated model}

Two scenarios are formed in the scenario forecasting unit - inertial (conservative) and innovative (target) changes in the values of the main initial indicators-the volume of passenger and freight transport work and specific (per unit of transport work, mileage, road length) GHG emissions, the increase in the length of public 
roads, changes in the number and structure of the vehicle fleet by type of power plants and type of fuel used [3].

At the same time, measures are indicated for the implementation of which these values can be achieved. Scenarios are based on the forecast of the long-term socio-economic development of a region or state and trends in the technological development of the automobile industry, automobile transport and road facilities.

In the inertial scenario of performance assessment, for example, for the Russian Federation, only previously adopted policy measures to promote low-carbon development are implemented, including measures to improve energy efficiency, the development of nuclear energy, non-traditional energy sources. The innovative scenario is characterized by a significant increase in the requirements for environmental friendliness and energy efficiency of road transport development. Within the framework of the scenario, it is planned to change the structure of the fuel and energy resources used, implement a more resource-intensive model for the state and business management of transport development with a significant increase in costs for the development of transport infrastructure, the implementation of high-tech projects and human development. In both scenarios, it is expected to develop and put into operation the mechanisms of state and market regulation, providing for the implementation of regulatory, legal, organizational, engineering and economic measures with different intensity of input in time and coverage of the territory in three directions:

1) rise the energy efficiency of vehicles and transport technologies using traditional motor fuels;

2) diversification of the use of different energy sources for vehicles with lower GHG emissions;

3) mobility management - reduction of excessive, irrational, unjustified movement of goods and passengers, containment of hypermobility of the population through the development of transport systems that use advanced communication capabilities between cars, road infrastructure and the car, car and man.

The implementation timeframes for the inertial scenario are shifted by 5-7 years compared to the innovation one and implemented in smaller volumes.

The activities of the first direction include: development and implementation of new energy-saving and environmentally friendly vehicles and technologies in transport; formation of the optimal structure (promotion of park renewal) of the rolling stock by managing the processes of its replenishment and disposal; promotion of sustainable mobility through improved emission standards (regulation of specific $\mathrm{CO}_{2}$ emissions), the development of non-motorized modes of transport; maintenance of the technical condition of the rolling stock and transport infrastructure in a regulatory state; encouraging the consumer to make a choice of low-carbon vehicles, etc.

Activities of the second direction are related to the development of: energy-efficient production of alternative fuels and vehicles capable of working on them, electrification of road transport; refueling infrastructure for using alternative fuels.

Activities of the third direction include: management of demand for transport services; formation of a rational structure of transport networks in cities and agglomerations; formation of a "smart" system of charging road tolls (by distance traveled, the mass of the vehicle, the level of their energy and environmental efficiency), etc. In the formation of the forecast values of specific $\mathrm{CO}_{2}$ emissions (per unit length of road) during the construction, maintenance, repair of roads of different categories in the Russian Federation, it was accepted for both scenarios that these values will not change significantly in the entire forecast interval compared to 2015. The projected values of specific GHG emissions per unit of transport work are set as targets in the Transport strategy of the Russian Federation and are given in table 3.

Table 3 Forecast values of specific GHG emissions by road transport per unit of transport work in the pilot region and state

\begin{tabular}{|c|c|c|c|c|c|c|c|c|}
\hline \multirow{2}{*}{$\begin{array}{l}\text { Name } \\
\text { indicator }\end{array}$} & \multirow{2}{*}{ evel } & \multirow{2}{*}{2015} & \multicolumn{2}{|c|}{2020} & \multicolumn{2}{|r|}{2025} & \multicolumn{2}{|c|}{2030} \\
\hline & & & target & conservative & target & conservative & target & conservative \\
\hline \multirow{2}{*}{$\begin{array}{l}\text { Road transport, } \\
\mathrm{g} \quad \mathrm{CO}_{2} \text {-equiv./t } \\
\mathrm{km}\end{array}$} & Region & 806.9 & 678.3 & 662.3 & 547.9 & 631.8 & 384.6 & 563.2 \\
\hline & Country & 940.6 & 790.8 & 772.0 & 638.8 & 736.5 & 448.4 & 656.6 \\
\hline \multirow{2}{*}{ 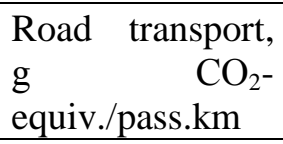 } & $\mathrm{Re}$ & 1732. & 1684.2 & 1143.2 & 1492.8 & 1644.8 & 1158.8 & 1526.7 \\
\hline & Country & 1731.2 & 1682.7 & 1639.0 & 1491.5 & 1643.4 & 1157.8 & 1525.3 \\
\hline \multirow{2}{*}{$\begin{array}{l}\text { Road facilities, } \mathrm{t} \\
\mathrm{CO}_{2} \text {-equiv./km }\end{array}$} & Region & 10.38 & 9.5 & 9.9 & 8.9 & 9.3 & 8.3 & 8.8 \\
\hline & Country & 12.12 & 11.09 & 11.5 & 10.4 & 10.9 & 9.7 & 10.3 \\
\hline
\end{tabular}


The volumes of consumption of different types of fuel (electricity) by the car fleet for a given forecast period were determined by the method given in [6], based on the number of passenger, light commercial, freight exchanges and buses with different types of engines, their specific fuel consumption $(\mathrm{g} / \mathrm{km})$ and the weighted average annual mileage of passenger, light commercial, freight trucks and buses [6]. The volumes of consumption of different types of fuel (electricity) were established taking into account the balance of fuel consumption and the results of calculations under the COPERT program [9] or NIIAT [4], and for the forecast period - taking into account the trends of increasing fuel efficiency of vehicles ( $2 \%$ per year). The assessment of the impact of these indicators, especially the weighted average annual mileage, on the reliability of the estimation of gross GHG emissions by the vehicle fleet according to this method is considered in detail in [6].

\section{Numerical implementation of the model to assess GHG emissions of road transport}

The model was implemented on the example of estimation of gross GHG emissions by road transport of the pilot region (St. Petersburg and Leningrad region) and the Russian Federation.

When performing estimates of gross GHG emissions by vehicles of the pilot region in 2015 on a three-level model, a significant discrepancy in the values of the calculated values of gross GHG emissions was established (see table. 4), as well as input data for models of all three levels contained in the forms of state statistical reporting, in particular annual mileage, fuel consumption, environmental class of all vehicles in the region of legal entities and individuals.

Table 4 Estimation of gross GHG emissions by road transport in the pilot region in 2015 according to the methods of different levels of detail of initial data, million tons of $\mathrm{CO}_{2}$

\begin{tabular}{|lccc|}
\hline Name & Level 1 & Level 2 & Level 3 \\
\hline $\begin{array}{l}\text { Mobile and stationary (car service } \\
\text { network) facilities of motor transport }\end{array}$ & $2.69 *$ & $7.39 * *$ и 8.29 & $7.28^{* *}$ и 8.13 \\
\hline $\begin{array}{l}\text { Stationary facilities of motor transport } \\
\text { (road network) }\end{array}$ & 0.109 & 0.114 & - \\
\hline Total & 2.799 & $7.504-8.404$ & $7.28-8.13$ \\
\hline
\end{tabular}

* - GHG emissions by cars of individuals are not taken into account (according to official statistics); ** mobile emission sources only

\section{Results and Discussion}

As a result of verification of the initial data and the results of GHG emissions assessment by Models of levels 1-3 using the developed intelligent machine learning system, it was found that the GHG emissions by motor transport in the region in 2015 amounted to 8.34 million tons of $\mathrm{CO}_{2}$, including from mobile and stationary (car service network) objects of road transport -8.23 million tons of $\mathrm{CO}_{2}$, road network -0.112 million tons of $\mathrm{CO}_{2}$ (GHG emissions in the life cycle of Federal, regional and inter-municipal roads of the region were taken into account). Table 5 shows the results of the implementation of the model of the forecast estimation of gross GHG emissions by road transport of the pilot region and the Russian Federation only using the Level 1 model.

Table 5 Results of the forecast of gross GHG emissions by road transport of the region and the state on the model of Level 1, million tons of $\mathrm{CO}_{2}$

\begin{tabular}{|l|c|c|c|c|c|c|c|c|}
\hline \multirow{2}{*}{$\begin{array}{l}\text { Name } \\
\text { indicator }\end{array}$} & \multirow{2}{*}{ Level } & 2015 & \multicolumn{2}{|c|}{2020} & \multicolumn{2}{|c|}{2025} & \multicolumn{2}{|c|}{2030} \\
\cline { 4 - 10 } & & target & conservative & target & conservative & target & conservative \\
\hline $\begin{array}{l}\text { Mobile and } \\
\text { stationary } \\
\text { facilities of motor } \\
\text { transport }\end{array}$ & Region & 8.23 & 8.34 & 7.24 & 8.63 & 8.35 & 7.16 & 8.62 \\
\hline
\end{tabular}


PEN Vol. 7, No. 1, June 2019, pp.465- 473

\begin{tabular}{|l|l|c|c|c|c|c|c|c|}
\hline $\begin{array}{l}\text { Stationary } \\
\text { facilities of motor } \\
\text { transport (road } \\
\text { network) }\end{array}$ & Region & 0.112 & 0.11 & 0.114 & 0.113 & 0.116 & 0.12 & 0.118 \\
\cline { 2 - 9 } & Country & 12.67 & 12.46 & 12.91 & 12.87 & 13.14 & 13.63 & 13.42 \\
\hline \multirow{2}{*}{ TOTAL } & Region & $\mathbf{8 . 3 4}$ & $\mathbf{8 . 4 5}$ & $\mathbf{7 . 3 5}$ & $\mathbf{8 . 7 4}$ & $\mathbf{8 . 4 7}$ & $\mathbf{7 . 2 8}$ & $\mathbf{8 . 7 4}$ \\
\cline { 2 - 9 } & Country & $\mathbf{2 3 1 . 8 4}$ & $\mathbf{2 3 0 . 7 0}$ & $\mathbf{2 2 3 . 5 3}$ & $\mathbf{2 2 1 . 2 3}$ & $\mathbf{2 2 6 . 1 2}$ & $\mathbf{2 0 3 . 1 7}$ & $\mathbf{2 2 4 . 3 7}$ \\
\hline
\end{tabular}

The calculations showed that it is expected to reduce gross GHG emissions by road transport in Russia in 2030 compared to 2015 by $3.2 \ldots 12.4 \%$. At the same time, for the pilot region in the considered forecast period, the reduction of gross GHG emissions by road transport by $12.7 \%$ can be achieved only with the implementation of the innovative scenario. Under the inertial scenario, gross GHG emissions by road are expected to increase by $4.8 \%$.

At the same time, both for the pilot region and for the state as a whole, a noticeable decrease in gross GHG emissions by road is expected in the period after 2025 due to the intensive replacement of cars with electric vehicles and hybrids on oil fuel, changes in the transport behavior of the population, the development of public passenger transport and cycling, the introduction of unmanned vehicles, etc.

\section{Conclusion}

A three-level model for estimating greenhouse gas (GHG) emissions by mobile and stationary road transport facilities of a state or region, proposed in this article, takes account into GHG emissions from a vehicle fleet (mobile objects) and road transport infrastructure (network of car services, road network of various categories).

Additionally, it has been developed the intellectual system which evaluates the reliability of the array of initial data, by increasing the range and adjusting (if necessary) the values of individual indicators, as the result we achieving the convergence of the calculating GHG emissions from motor vehicles according to the models of all three levels of assessment. This ensures verification of the obtained gross GHG emissions.

Evaluation of greenhouse gas emissions using three-level model was carried out for St. Petersburg and the Leningrad Region (Russian Federation), they shown the possibility of reducing by 2030 by $3.2 \ldots 12.4 \%$ of gross GHG emissions by motor transport of the Russian Federation in comparison with 2015. For St. Petersburg and the Leningrad Region, both the reduction of gross GHG emissions by road transport (12.7\% innovative scenario) and their growth (4.8\% inertial scenario) are expected during the forecast period. At the same time, both for the St. Petersburg and the Leningrad Region and for the state as a whole, a significant reduction in gross GHG emissions by road transport is expected in the period after 2025 due to the intensive replacement of cars on oil fuel by electric vehicles and hybrids, changes in the transport behavior of the population, the development of public passenger transport and cycling, the introduction of autonomous vehicles, etc. At the same time, both for the St. Petersburg and the Leningrad Region and for the state as a whole, a significant reduction in gross GHG emissions by road transport is expected in the period after 2025 due to the intensive replacement of cars operating on oil fuel, by electric vehicles and hybrids, also by changes in the transport behavior of the population and the development of public passenger transport, cycling, the introduction of unmanned vehicles, etc.

\section{References}

[1] Yu. Trofimenko, V. Komkov and V. Donchenko, "Problems and prospects of sustainable low carbon development of transport in Russia. International Conference on Sustainable Cities," IOP Publishing. IOP Conf. Series: Earth and Environmental Science, vol. 177, pp. 11, 2018.

[2] H.S. Eggleston, L. Buendia, K. Miwa, T. Ngara, K. Tanabe, "2006 IPCC Guidelines for National Greenhouse Gas Inventories, Volume 2, Energy," available at: https://www.ipccnggip.iges.or.jp/public/2006gl/pdf/2_Volume2/V2_0_Cover.pdf.

[3] Yu. Trofimenko, V. Komkov, T. Grigoryeva, "Forecast of the vehicle fleet size and structure in Russian Federation by ecological class, a type of power installations and a fuel type for the period up to 2030," Proceedings of the Sixth International Environmental Congress (Eighth International Scientific-Technical 
Conference) «Ecology and Life Protection of Industrial-Transport Complexes - Samara: izdatelstvo Samarskogo Nayshnogo Sentra, pp. 311-326, 2017.

[4] V. Donchenko, Y. Kunin, A. Ruzski, V. Mekhonoshin, L. Barishev, Y. Trofimenko, "Estimated atmospheric emission from motor transport in Moscow based on transport model of the city," Transportation Research Procedia, vol.1, pp. 2649-2658, 2016.

[5] V. Lukanin, A. Buslaev, Y. Trofimenko, M. Yashina, "Modeling and Optimal Control of Transport Flows in Megapolis," International Journal of Vehicle design, vol. 19(3), pp. 267-281. 1998.

[6] Y. Trofimenko, V. Ginzburg, V. Komkov, V. Lytov, "Influence of the motor vehicle parking structure by fuel type and ecological class on greenhouse gas emissions," The Russian Automobile and Highway Industry Journal. vol. 15(6), pp. 898-910, 2018.

[7] F. Eibe, M. Hall, "Data mining: practical machine learning tools and techniques," 3rd. ed, 607 p, 2011, avaliable at: https://b-ok.org/book/1043456/709263

[8] EMEP/EEA air pollutant emission inventory guidebook 2016. Technical guidance to prepare national emission inventories. EEA Report, Copenhagen, 2016, avakiable at: https://www.eea.europa.eu//publications/emep-eea-guidebook-2016

[9] COPERT Versions, available at: http://www.emisia.com/utilities/copert/versions/

[10] V. Lukanin, A. Buslaev, Y. Trofimenko, M. Jashina "Avtotransportnye potoki i okruzhajushhaja sreda (Road traffic and environment)," Moscow, INFRA-M, pp. 408, 1998. 